\title{
Hyperviscous Semen Causes Poor Sperm Quality and Male Infertility through Induction of Oxidative Stress
}

\author{
Asghar Beigi Harchegani ${ }^{a} \quad$ Hamid Rahmani $^{b}$ Eisa Tahmasbpour ${ }^{c} \quad$ Alireza Shahriary $^{b}$ \\ aDepartment of Medical Genetics, Faculty of Medicine, Shahid Beheshti University of Medical Sciences; \\ ${ }^{b}$ Chemical Injuries Research Center, System Biology and Poisonings Institute, Baqiyatallah University of Medical Sciences; \\ 'Laboratory of Regenerative Medicine \& Biomedical Innovations, Pasteur Institute of Iran, Tehran, Iran
}

\author{
Key Words \\ Antioxidants • Lipid peroxidation - Male infertility • \\ Oxidative stress $\cdot$ Semen hyperviscosity
}

\begin{abstract}
Background/Aims: Semen hyperviscosity (SHV) is one of the significant factors involved in poor semen quality and male infertility. It also leads major problems during assisted reproduction techniques and in vitro fertilization process. Although influence of SHV on sperm quality, fertilization rate and male infertility have been widely considered, molecular and cellular mechanisms for these abnormalities are not well understood. In this review, we aimed to discuss the proposed cellular and molecular mechanisms of SHV on male reproductive system, the importance of oxidative stress (OS) and the mechanisms by which SHV induces OS and impairment of other antioxidants. Methods: A PubMed/Medline and EMBASE search was performed using keywords: "hyperviscosity semen", "oxidative stress", and "male infertility". Conclusion: OS induced by reactive oxygen species can be considered as a major mechanism in patients with hyperviscosity semen that is associated with DNA fragmentation, lipid peroxidation and sperm membrane disintegrity, apoptosis, depletion of antioxidants, and subsequently poor sperm quality and male infertility. Therefore, antioxidant therapy may improve main pathological effects of hyperviscosity semen, especially oxidative damages and inflammation, on sperm qual-
\end{abstract}

\section{KARGER}

Fax +4161306 1234

E-Mail karger@karger.com

www.karger.com
(C) 2019 The Author(s)

Published by S. Karger AG, Basel Open access

This article is licensed under the Creative Commons AttributionNonCommercial-NoDerivatives 4 . International License (CC BYNonCommercial-NoDerivatives 4.0 International License (CC BYUC-ND) (htp://ww.kargercom/Services/OpenAccessLicense). ity and function. Further, randomized controlled studies are necessary to confirm these results and make a comparison between effects of various antioxidants such as $\mathrm{N}$-acethylcysteine and Curcumin on fertility problem in patients with hyperviscous semen.

(C) 2019 The Author(s)

Published by S. Karger AG, Basel

\section{Introduction}

Infertility is now considered as one of the significant health problems among couples worldwide. There are many factors that affect sperm parameters, function and subsequently male fertility [1]. Genetic abnormalities, molecular mutations, hormonal defects, impaired spermatogenesis, nutritional deficiency of some trace elements and vitamins, obstructive problems and structural damages such as varicocele, environmental agents, and life style are grouped as popular factors that affect human sperm function and fertilization processes $[2,3]$.

Semen hyperviscosity (SHV), which is characterized by a thick and coagulated appearance, is a condition that affects the physical and chemical characteristics of human seminal fluid [4]. Semen with normal viscose plays critical roles for sperm function and fertilization process. It facilitates the entry of spermatozoa into cervical mucus [5], maintains sperm swimming speed after mucus pen-

$\begin{array}{ll}\text { Alireza Shahriary } & \text { Eisa Tahmasbpour } \\ \text { Chemical Injuries Research Center } & \text { Laboratory of Regenerative Medicine \& } \\ \text { System Biology and Poisonings Institute } & \text { Biomedical Innovations } \\ \text { Baqiyatallah University of Medical Sciences } & \text { Pasteur Institute of Iran } \\ \text { Tehran (Iran) } & \text { Tehran (Iran) } \\ \text { E-Mail Shahriary961@gmail.com } & \text { E-Mail tahmasb62@gmail.com }\end{array}$

Alireza Shahriary System Biology and Poisonings Institute Tehran (Iran)

E-Mail Shahriary961@gmail.com 


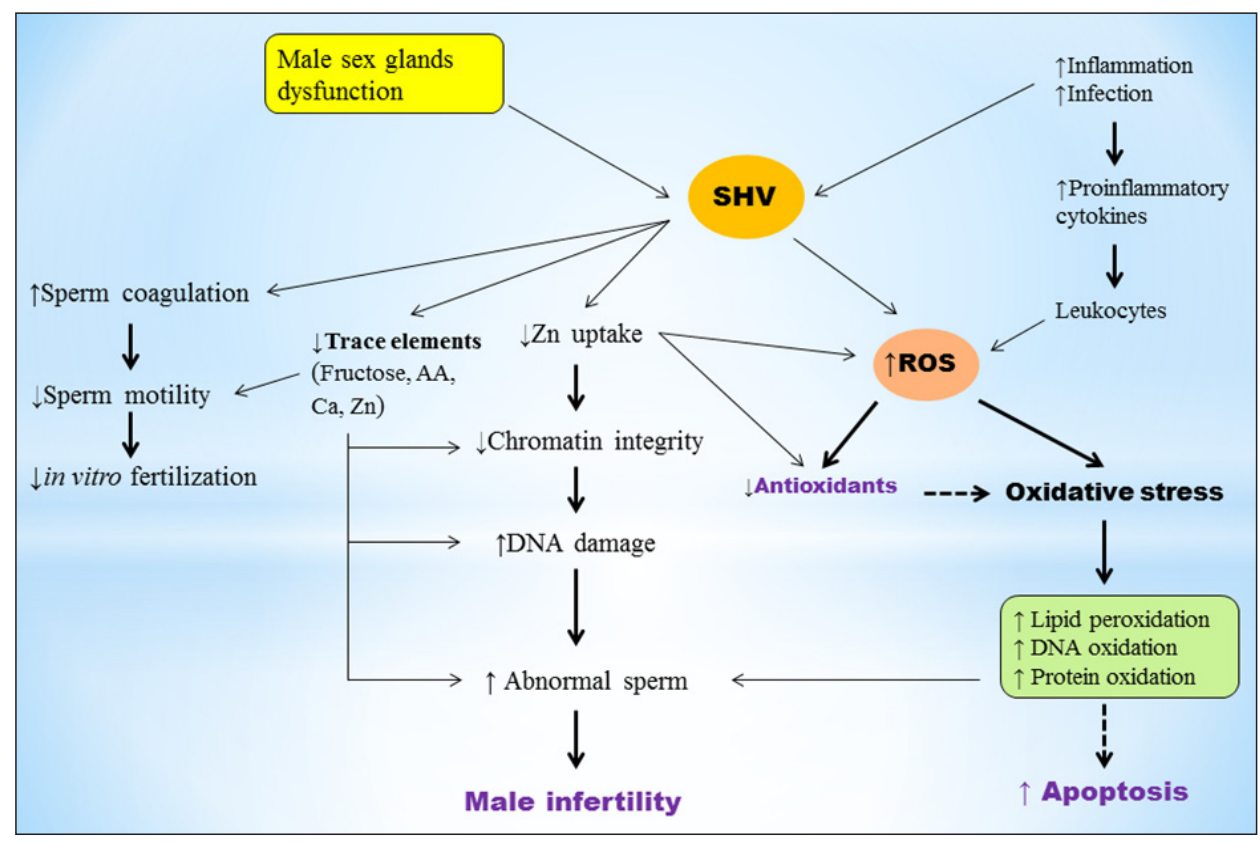

Fig. 1. Proposed mechanisms for the effects of hyperviscous semen on poor sperm quality and male infertility. SHV decreases sperm quality and fertilization rate through several mechanisms including: impairment of sperm motility, increased number of inflammatory cytokines and leukocytes, enhanced ROS production and OS, reduced uptake of Zn, impairment of seminal plasma antioxidants, changes in some trace elements and apoptosis. OS induced by overproduction of ROS and antioxidants impairment is the major mechanism of SHV which is associated with sperm DNA oxidation, membrane lipid peroxidation, and subsequently poor sperm quality.

etration, regulates the distribution of surface charges on the sperm membrane during the maturation process [6], prevents of the lipid peroxidation reaction [7], and maintains the chromatin integrity of spermatozoa [8]. SHV is probably caused by dysfunction, infection and inflammation of the male accessory glands or the immune system [9]. Recent studies have reported that SHV occurs in $12-29 \%$ of ejaculates and can be considered as a main reason for male infertility [9-11]. It has been shown to be contributed in poor sperm motility and semen quality, as well as a poor outcome with in vitro fertilization [12]. Although the pathogenic aspects of SHV are now clarified, the exact mechanism in which hyperviscous semen is associated with abnormal sperm and male infertility are still not clear. Altered sperm motility, technical difficulties in in vitro fertilization, inflammation, oxidative stress (OS) and changes in trace elements are the major proposed mechanisms of SHV on male infertility (fig.1). In the following sections we will discuss these proposed mechanisms in which SHV induces impaired spermatogenesis and male infertility.

\section{Sperm Motility}

Impairment of normal sperm movement is considered as one of the significant mechanisms by which SHV leads to male infertility [13]. Numerous studies have demonstrated that SHV is associated with reduced sperm motility because of a trapping effect of hyperviscous semen [11]. It is contributed to the pathogenesis of different forms of asthenozoospermia and male infertility [14]. Recent studies have found significant negative correlations between SHV and sperm motility, grade of motility, total motile sperm and sperm vitality $[11,14$, 15]. Normal motility of sperm is a critical factor for the entry of sperm into the cervical mucus, sperm-egg interaction and fertilization process. Therefore, hyperviscous 
semen traps sperm cells in the fibrous or mucoid mass and prevents their normal progression through the female genital tract.

\section{In vitro Fertilization}

As seminal plasma has an important role in events leading to fertilization, SHV can also lead to in vivo and in vitro complications which have negative consequences in assisted reproductive technology setting [11, 12]. Hyperviscous semen causes certain difficulties for proper separation of spermatozoa and its number. SHV is reported to be associated with poor outcome of controlled ovarian hyperstimulation and intrauterine insemination [16]. It reduces fertilization rates in patients undergoing in vitro fertilization programs [11]. SHV can also result in certain technical difficulties in the handling of semen samples, when using Percoll gradients to prepare sperm for in vitro fertilization [11].

\section{Deficiency in Zinc Uptake}

SHV, which is caused by the seminal vesicle hypofunction, can lead to enhanced proportion of prostatic fluid that contains zinc (Zn) [12]. Seminal plasma zinc is originated primarily from the prostate gland and may reflect prostatic secretary function [17]. Increased level of zinc in absence of a seminal vesicle zinc ligand can inhibit sperm chromatin decondensation which may result in chromatin instability [11]. Recent studies have reported increased defects in chromatin integrity and packaging in patients with hyperviscous semen [18]. Poor chromatin packaging or integrity is associated with sperm DNA damage and increased risk of infertility and pregnancy outcome $[19,20]$. Furthermore, zinc has antioxidative properties and plays as a cofactor for different antioxidants such as $\mathrm{Cu} / \mathrm{Zn}$-superoxide dismutase [2123]. Given the antioxidative properties of zinc, reduced intake of zinc in patients with HSV can result in OS and subsequently sperm DNA damage, membrane lipid peroxidation, apoptosis and poor semen quality [24, 25].

\section{Changes in Trace Elements}

SHV not only stimulates overproduction of reactive oxygen species (ROS) and oxidative damages through induction of inflammation, but also it leads to alterations in the contents of seminal plasma fructose, ascorbic acid, calcium, and zinc, which in turn exert negative influences on sperm function or fertilizing capacity of spermatozoa [14]. Mahran et al. [14] reported a significant negative correlation between SHV and seminal plasma levels of fructose, ascorbic acid, zinc, and calcium. They also observed that enhanced level of leukocytes is correlated negatively with ascorbic acid, fructose, zinc and calcium concentrations. In another study, Gonzales et al. [26] reported reduced levels of fructose in SHV patients. These trace elements are necessary for the spermatogenesis, energy production, normal function of spermatozoa, sperm motility, protection of sperm against ROS and fertilization process $[21,27-30]$. Therefore, reduced levels of these elements in patients with hyperviscous semen exert negative impacts on spermatogenesis, semen quality and male fertility. Furthermore, fructose and ascorbic acid are biomarkers of seminal vesicle function, while calcium and zinc are biomarkers of prostatic function. Thus, physical analysis of ejaculate including viscosity can be clinically useful for the evaluation of the secretory activity of the these male accessory glands [14].

\section{OS}

OS induced by free radicals, especially ROS, is now considered as one of the main idiopathic factors that affect human spermatozoa [3]. It is now considered as one of the main reason for male infertility, that is, 30 to $40 \%$ of infertile men have enhanced contents of ROS in their seminal plasma [31, 32]. Recent studies have indicated that OS is the main mechanism of HSV effects on poor semen quality $[4,33]$. OS is a condition in which free radicals contents overwhelm the levels of antioxidants. ROS such as hydroxyl radicals $\left(\mathrm{OH}^{*}\right)$, superoxide anion radical $\left(\mathrm{O}_{2}{ }^{\circ-}\right)$ and hydrogen peroxide $\left(\mathrm{H}_{2} \mathrm{O}_{2}\right)$ are very reactive agents that interact with cellular macromolecules to compensate their deficit electron [21, 30, 34]. Although free radicals are essential for sperm capacitation and acrosome reaction at physiological concentration, they can oxide DNA, proteins and lipids at high concentrations [35].

Human sperm cells are particularly susceptible to ROS because they have high levels of polyunsaturated fatty acids at their membrane. Additionally, they lose most of their cytoplasmic antioxidants during spermiogenesis [36, 37]. Therefore, enhanced contents of ROS and subsequently reduced levels of seminal plasma antioxidants can increase sperm DNA damage, membrane 
lipid peroxidation, and eventually sperm cells damage and increased risk of male infertility [38]. 8-OHdG, malondialdehyde and protein carbonyl are biomarkers of DNA, protein and lipid oxidation. Numerous studies reported increased contents of these biomarkers in seminal plasma of infertile patients.

Leukocytes, especially neutrophils and macrophages, and dysfunctional spermatozoa are the major endogenous sources of ROS production in human semen [39, 40]. Overproduction of ROS in human semen affects sperm cells mitochondrial function and subsequently sperm motility [41]. During infection or inflammation, leukocytes can discharge up to 100 times more ROS than normal and contribute to OS $[42,43]$. A great number of studies have reported leukocytospermia in infertile patients [31, 40, $44,45]$. Increased number of seminal plasma leukocytes and proinflammatory cytokines such as IL-6, IL-8, and tumor necrosis factor is associated with overproduction of ROS, oxidative damages to sperm DNA, membrane lipids and subsequently apoptosis and sperm abnormalities [46].

Leukocytes are particularly responsible in the development of SHV, as they are increased during the infection and produce high levels of ROS [47]. Patients with hyperviscous semen have high percentage of leukocytes compared with non-hyperviscous men. Recent studies have indicated a significant positive correlation between leukocytospermia and hyperviscosity semen [14]. In a study, Mahran et al. [14] observed leukocytospermia in $37.5 \%$ of the infertile men with hyperviscosity semen. Furthermore, increased number of leukocytes in SHV patients was correlated negatively with sperm motility and vitality. They suggested that SHV seems to be a result of infection or inflammation in $75 \%$ cases. Elis et al. [48] proposed that anti-inflammatory therapy can successfully treat mild SHV.

Recent evidences have demonstrated that OS induced by ROS is the major mechanism of HSV on poor quality of sperm and male infertility among patients with hyperviscous semen $[4,33]$. OS has been also reported to be associated with hyperviscous blood $[49,50]$. In a study by Harisa et al. [49] they observed a rise in malondialdehyde and protein carbonyl levels in patients with higher blood viscosity. They also showed that increasing concentrations of malondialdehyde and protein carbonyl is correlated with increasing degrees of viscosity. In another study by Kasperczyk et al. [50] they reported whole blood viscosity is associated with OS, erythrocyte aggregation and decreased level of malondialdehyde.

Although these data suggest that OS is a contributor to SHV, the exact mechanism in which SHV increase
OS is not well understood. One of these mechanisms is probably related to increased level of abnormal sperms in patients with SHV. Patients with hyperviscous semen have higher percentage of abnormal spermatozoa in their semen compared to healthy individuals [4]. As dysfunctional spermatozoa are one of the major sources of ROS production, increased number of immature and abnormal sperm cells in SHV patients may explain the higher existence of OS in their semen. Furthermore, the number of leukocytes, as the other significant source of ROS generation, in semen of HSV patients is greater than that in men with normal semen. Therefore, increased number of leukocytes as a result of inflammation or infection in HSV patients can be considered as the other main reasons for overproduction of ROS and OS in these patients. Enhanced ROS in SHV patients can decline the effective concentration of seminal plasma antioxidants and as the result increases the harmful effects of ROS to spermatozoa. Thus, impairment of semen antioxidants can be considers as one of the other main mechanism SHV action on poor semen quality [4]. In a study by Siciliano et al. [51] they reported a severe impairment of both the high and low molecular weight antioxidants in SHV patients. Layali et al. [4] indicated that hyperviscous semen impairs seminal plasma total antioxidants capacity, which is eventually associated with sperm membrane lipid peroxidation. Similarly, Aydemir et al. [33] found higher malondialdehyde levels in seminal plasma of patients with hyperviscous semen compared to non-viscous individuals. These results suggest that increased number of abnormal sperms and inflammatory cytokines as well as severe impairment of antioxidants, which are associated with increased sperm membrane lipid peroxidation, can be the main reason for low quality of sperm among SHV patients.

\section{Conclusion}

SHV can be considered as one of the main reason for poor quality of sperm in men with hyperviscous semen. Impairment of sperm motility, deficiency in zinc uptake, changes in trace elements, poor quality of semen, increased number of leukocytes and ROS production, and OS are the major mechanisms in which SHV induces sperm abnormalities and male infertility. Impairment of seminal plasma antioxidant and OS is the major mechanism of SHV, which can be associated with sperm DNA damage, membrane lipid peroxidation, sperm chromatin instability and low fertilization rate. Therefore, treatment 
with antioxidants may be helpful in patients showing hyperviscous semen to protect sperm cells by oxidative damages. However, further studies into possible treatments for and causes of SHV are essential in order to improve fertility and the success of assisted reproductive technology procedures.

\section{Acknowledgments}

We are deeply indebted to past and present collaborators.

\section{References}

1 Tahmasbpour E, Balasubramanian D, Agarwal A: A multi-faceted approach to understanding male infertility: gene mutations, molecular defects and assisted reproductive techniques (ART). J Assist Reprod Genet 2014;31:1115-1137.

2 Agarwal A, Wang SM: Clinical relevance of oxidation-reduction potential in the evaluation of male infertility. Urology 2017; 104:84-89.

-3 Agarwal A, Roychoudhury S, Sharma R, Gupta S, Majzoub A, Sabanegh E: Diagnostic application of oxidation-reduction potential assay for measurement of oxidative stress: clinical utility in male factor infertility. Reprod Biomed Online 2017;34:48-57.

-4 Layali I, Tahmasbpour E, Joulaei M, Jorsaraei SG, Farzanegi P: Total antioxidant capacity and lipid peroxidation in semen of patient with hyperviscosity. Cell J 2015;16:554-559.

-5 Overstreet JW, Coats C, Katz DF, Hanson FW: The importance of seminal plasma for sperm penetration of human cervical mucus. Fertil Steril 1980;34:569-572.

6 Clavert A, Montagnon D, Cranz C, Rumpler Y: Soluble seminal fluid proteins from various animal species. Arch Androl 1985:14:177-179.

-7 Jones R, Mann T, Sherins R: Peroxidative breakdown of phospholipids in human spermatozoa, spermicidal properties of fatty acid peroxides, and protective action of seminal plasma. Fertil Steril 1979;31:531-537.

-8 Huret JL: Nuclear chromatin decondensation of human sperm: a review. Arch Androl 1986;16:97-109.

-9 Andrade-Rocha F: Physical analysis of ejaculate to evaluate the secretory activity of the seminal vesicles and prostate. Clin Chem Lab Med 2005;43:1203-1210.

10 Stephanus du Plessis S, Gokul S, Agarwal A: Semen hyperviscosity: causes, consequences, and cures. Front Biosci (Elite Ed) 2013;5:224-231

11 Esfandiari N, Burjaq H, Gotlieb L, Casper RF: Seminal hyperviscosity is associated with poor outcome of in vitro fertilization and embryo transfer: a prospective study. Fertil Steril 2008;90:1739-1743.

-12 Du Plessis SS, Gokul S, Agarwal A: Semen hyperviscosity: causes, consequences, and cures. FrontBiosci(EliteEd) 2013;5:224-231.
13 Mendeluk GR, Munuce MJ, Carizza C, Sardi M, Bregni C: Sperm motility and ATP content in seminal hyperviscosity. Arch Androl 1997;39:223-227.

14 Mahran Z, El-Eraki Saleh M: Human semen hyperviscosity: prevalence and effects on physical and biochemical semen parameters in subfertile Egyptian men. Egypt J Dermatol Venerol 2014;34:135-139.

15 Elzanaty S, Malm J, Giwercman A: Visco-elasticity of seminal fluid in relation to the epididymal and accessory sex gland function and its impact on sperm motility. Int J Androl 2004;27:94-100.

16 Esfandiari N, Gotlieb L, Casper RF: Seminal hyperviscosity is associated with poor outcome of controlled ovarian stimulation and intrauterine insemination: a prospective study. Int J Fertil Womens Med 2006;51:21-27.

17 Khan MS, Zaman S, Sajjad M, Shoaib M, Gilani G: Assessment of the level of trace element zinc in seminal plasma of males and evaluation of its role in male infertility. Int J Appl Basic Med Res 2011;1:93-96.

18 Gopalkrishnan K, Padwal V, Balaiah D: Does seminal fluid viscosity influence sperm chromatinintegrity? Arch Androl 2000;45:99-103.

19 Gorczyca W, Traganos F, Jesionowska H, Darzynkiewicz Z: Presence of DNA strand breaks and increased sensitivity of DNA in situ to denaturation in abnormal human sperm cells: analogy to apoptosis of somatic cells. Exp Cell Res 1993;207:202-205.

-20 Manicardi GC, Bianchi PG, Pantano S, Azzoni P, Bizzaro D, Bianchi U, Sakkas D: Presence of endogenous nicks in DNA of ejaculated human spermatozoa and its relationship to chromomycin A3 accessibility. Biol Reprod 1995;52:864-867.

21 Colagar AH, Marzony ET, Chaichi MJ: Zinc levels in seminal plasma are associated with sperm quality in fertile and infertile men. Nutr Res 2009;29:82-88.

22 Zhou X, Li Y, Li Z, Cao Y, Wang F, Li C: Effect of dietary zinc on morphological characteristics and apoptosis related gene expression in the small intestine of Bama miniature pigs. Acta Histochem 2017;119:235-243.
23 Perera NC, Godahewa GI, Lee J: Copper-zinc-superoxide dismutase (CuZnSOD), an antioxidant gene from seahorse (Hippocampus abdominalis); molecular cloning, sequence characterization, antioxidant activity and potential peroxidation function of its recombinant protein. Fish Shellfish Immunol 2016;57:386-399.

-24 Zheng JL, Zeng L, Xu MY, Shen B, Wu CW: Different effects of low- and high-dose waterborne zinc on $\mathrm{Zn}$ accumulation, ROS levels, oxidative damage and antioxidant responses in the liver of large yellow croaker Pseudosciaena crocea. Fish Physiol Biochem 2017;43:153-163.

25 Seth R, Corniola RS, Gower-Winter SD, Morgan TJ Jr, Bishop B, Levenson CW: Zinc deficiency induces apoptosis via mitochondrial p53- and caspase-dependent pathways in human neuronal precursor cells. J Trace Elem Med Biol 2015;30:59-65.

26 Gonzales GF, Villena A: Influence of low corrected seminal fructose levels on sperm chromatin stability in semen from men attending an infertility service. Fertil Steril 1997;67:763-768.

27 Said L, Galeraud-Denis I, Carreau S, Saâd A: Relationship between semen quality and seminal plasma components: alpha-glucosidase, fructose and citrate in infertile men compared with a normospermic population of Tunisian men. Andrologia 2009;41:150-156.

28 Skandhan KP, Mazumdar B, Sumangala B, Jaya V: Seminal plasma calcium in normal and infertile patients. Urologia 2017;84:35-37.

29 Blomberg Jensen M, Gerner Lawaetz J, Andersson AM, Petersen JH, Nordkap L, Bang AK, Ekbom P, Joensen UN, Prætorius L, Lundstrøm P, Boujida VH, Lanske B, Juul A, Jørgensen N: Vitamin D deficiency and low ionized calcium are linked with semen quality and sex steroid levels in infertile men. Hum Reprod 2016;31:1875-1885

30 Colagar AH, Marzony ET: Ascorbic Acid in human seminal plasma: determination and its relationship to sperm quality. J Clin Biochem Nutr 2009;45:144-149.

31 Agarwal A, Virk G, Ong C, du Plessis SS: Effect of oxidative stress on male reproduction. World J Mens Health 2014;32:1-17. 
-32 Lanzafame FM, La Vignera S, Vicari E, Calogero AE: Oxidative stress and medical antioxidant treatment in male infertility. Reprod Biomed Online 2009;19:638-659.

-33 Aydemir B, Onaran I, Kiziler AR, Alici B, Akyolcu MC: The influence of oxidative damage on viscosity of seminal fluid in infertile men. J Androl 2008;29:41-46.

-34 Hosseinzadeh Colagar A, Pouramir M, Tahmasbpour Marzony E, Ali Jorsaraei SG: Relationship between seminal malondialdehyde levels and sperm quality in fertile and infertile men. Braz Arch Biol Technol 2009; 52:1387-1392.

35 Mahfouz RZ, du Plessis SS, Aziz N, Sharma R, Sabanegh E, Agarwal A: Sperm viability, apoptosis, and intracellular reactive oxygen species levels in human spermatozoa before and after induction of oxidative stress. Fertil Steril 2010;93:814-821.

36 Agarwal A, Nandipati KC, Sharma RK, Zippe CD, Raina R: Role of oxidative stress in the pathophysiological mechanism of erectile dysfunction. J Androl 2006;27:335-347.

-37 Agarwal A, Said TM: Oxidative stress, DNA damage and apoptosis in male infertility: a clinical approach. BJU Int 2005;95:503-507.

-38 Agarwal A, Prabakaran SA: Mechanism, measurement, and prevention of oxidative stress in male reproductive physiology. Indian J Exp Biol 2005;43:963-974.
39 Agarwal A, Mulgund A, Sharma R, Sabanegh E: Mechanisms of oligozoospermia: an oxidative stress perspective. Syst Biol Reprod Med 2014;60:206-216.

40 Oborna I, Fingerova H, Novotny J, Brezinova J, Svobodova M, Aziz N: Reactive oxygen species in human semen in relation to leukocyte contamination. Biomed Pap Med Fac Univ Palacky Olomouc Czech Repub 2009. 153:53-57.

41 Durairajanayagam D, Agarwal A, Ong C, Prashast P: Lycopene and male infertility. Asian J Androl 2014;16:420-425.

42 Agarwal A, Saleh RA, Bedaiwy MA: Role of reactive oxygen species in the pathophysiology of human reproduction. Fertil Steril 2003;79:829-843.

43 Lavranos G, Balla M, Tzortzopoulou A, Syriou V, Angelopoulou R: Investigating ROS sources in male infertility: a common end for numerous pathways. Reprod Toxicol 2012;34:298-307.

44 Henkel R, Kierspel E, Stalf T, Mehnert C, Menkveld R, Tinneberg HR, Schill WB, Kruger TF: Effect of reactive oxygen species produced by spermatozoa and leukocytes on sperm functions in non-leukocytospermic patients. Fertil Steril 2005;83:635-642.

45 Rengan AK, Agarwal A, van der Linde M, du Plessis SS: An investigation of excess residual cytoplasm in human spermatozoa and its distinction from the cytoplasmic droplet. Reprod Biol Endocrinol 2012;10:92.
46 Castiglione R, Salemi M, Vicari LO, Vicari $\mathrm{E}$ : Relationship of semen hyperviscosity with IL-6, TNF-alpha, IL-10 and ROS production in seminal plasma of infertile patients with prostatitis and prostato-vesiculitis. Andrologia 2014;46:1148-1155.

47 Quayle AJ, Xu C, Mayer KH, Anderson DJ: T lymphocytes and macrophages, but not motile spermatozoa, are a significant source of human immunodeficiency virus in semen. J Infect Dis 1997; 176:960-968.

48 Elia J, Delfino M, Imbrogno N, Capogreco F, Lucarelli M, Rossi T, Mazzilli F: Human semen hyperviscosity: prevalence, pathogenesis and therapeutic aspects. Asian J Androl 2009;11:609-615.

49 Harisa GI: Blood viscosity as a sensitive indicator for paclitaxel induced oxidative stress in human whole blood. Saudi Pharm J 2015; 23:48-54.

50 Kasperczyk A, Słowi ska-Ło y ska L, Dobrakowski M, Zalejska-Fiolka J, Kasperczyk $\mathrm{S}$ : The effect of lead-induced oxidative stress on blood viscosity and rheological properties of erythrocytes in lead exposed humans. Clin Hemorheol Microcirc 2014;56:187-195.

51 Siciliano L, Tarantino P, Longobardi F, Rago V, De Stefano C, Carpino A: Impaired seminal antioxidant capacity in human semen with hyperviscosity or oligoasthenozoospermia. J Androl 2001;22:798-803. 